\title{
El Calcolítico en el Alto Guadiana. Artesanos de cuentas en el interior peninsular: Los Parrales (Arenas de San Juan, Ciudad Real)
}

\section{Chalcolithic in the Upper Guadiana Basin (Ciudad Real, Spain). Craftsmen of beads in the inland of Iberian Peninsula: Los Parrales (Arenas de San Juan, Ciudad Real)}

\author{
LUIS BeníteZ de LUGO ENRICH ${ }^{1}$ \\ Honorio Javier Álvarez García ${ }^{2}$ \\ M. a ANTONIA GaRRIDO MartíneZ ${ }^{3}$ \\ FuenCISLA HERMANA MENDIOROZ ${ }^{3}$ \\ ManUel Molina Cañadas ${ }^{2}$ \\ JAIME MORALEDA SIERRA ${ }^{2}$
}

\begin{abstract}
RESUMEN
ABSTRACT

Doscientos noventa colgantes se han recuperado en un yacimiento arqueológico que se sitúa sobre un alto junto al río

Two hundred ninety beads have been found in an archaeological site located over a hill beside Cigüela river, tributary of

1 Profesor-tutor de Historia Antigua del Centro Asociado de la UNED en Valdepeñas (Ciudad Real).

2 ANTHRopos, S.L. www.anthroposclm.com. Con la colaboración de M. ${ }^{a}$ Carmen Arcos Domínguez (arqueóloga) y Jesús García del Castillo Crespo (zoólogo).

Agradecemos la valiosa aportación para la caracterización de las cuentas que nos han prestado los investigadores del Museo Nacional de Ciencias Naturales Dr. Rafael Araujo Armero, especialista en moluscos bivalvos dulceacuícolas, y Dra. Begoña Sánchez Chillón, conservadora de Paleontología y Geología.

${ }^{3}$ Museo Provincial de Ciudad Real.
\end{abstract}


Cigüela, uno de los principales afluentes del río Guadiana. El lugar se llama Los

Parrales y se localiza en el término municipal de Arenas de San Juan (Ciudad Real). La relevancia del hallazgo se deriva del elevado número de cuentas prehistóricas encontradas, de su asociación a cerámica campaniforme, del tipo de enclave en el que han aparecido y de las circunstancias del hallazgo: no han aparecido durante una excavación estratigráfica, sino en superficie. Los contactos culturales entre comunidades que habitaron los diversos sectores de la cuenca del río Guadiana, acreditados para otros momentos de la Prehistoria, constituyen una variable que puede ayudar a explicar este hallazgo.

\section{PALABRAS CLAVE}

Pectinidae, Chamalea Potomida, hueso, diente, concha, Campaniforme, Calcolítico, colgante oval, artesanía, río Cigüela, cuenca del río Guadiana, Arenas de San Juan, Ciudad Real, Castilla-La Mancha, interior peninsular, Meseta, prospección arqueológica.
Guadiana river. The place, in Arenas de San Juan (Ciudad Real), is called Los Parrales. Its significance is relevant because of the high number of elements found together, associated with Bell Baker pottery and the discovery's customs: not in an archaeological stratigraphy but in surface survey. Cultural contacts between people who lived in different sections of Guadiana river, confirmed in other prehistoric periods, can help to explain this find.

\section{KEY WORDS}

Pectinidae, Chamalea, Potomida, bone, tooth, shell, Bell Beaker Culture, Chalcolithic, oval pendant, bead, craftwork, Cigüela river, Guadiana basin, Arenas de San Juan, Ciudad Real, Castilla-La Mancha, inland of the Peninsula, Meseta, archaeological survey.

\section{INTRODUCCIÓN}

Una notable colección de casi trescientas cuentas elaboradas a partir de hueso y diente ha sido depositada en el Museo de Ciudad Real.

Los materiales proceden de Los Parrales (Arenas de San Juan, Ciudad Real), una localización calcolítica campaniforme del interior peninsular, ubicada encima de una pequeña elevación que domina el corredor constituido por la vega del río Cigüela, afluente principal del río Guadiana.

En el lugar no se aprecian restos de construcciones en superficie, pero sí una dispersión de restos malacológicos, tanto dulceacuícolas como de procedencia marina, y materiales arqueológicos diversos. No se han realizado en el yacimiento catas arqueológicas. Todos los materiales recuperados han sido encontrados en superficie.

El trabajo que ahora presentamos supone un esfuerzo combinado entre profesionales de la Arqueología y la Restauración, la UNED y el Museo de Ciudad Real, dirigido a dar a conocer los resultados de una intervención arqueológica. 
La iniciativa parte de la convicción sobre la ineludible necesidad de publicar los resultados de las cada vez más numerosas intervenciones arqueológicas, conscientes de que de nada sirve la acumulación de materiales e informes en los almacenes y anaqueles de la Administración competente si éstos no son presentados a la comunidad científica y puestos, de alguna forma, al servicio de la sociedad.

\section{CIRCUNSTANCIAS DEL HALLAZGO}

Las prospecciones de superficie desarrolladas para la elaboración de la Carta Arqueológica del término municipal de Arenas de San Juan (Ciudad Real) permitieron documentar en 2004 el yacimiento denominado Los Parrales ${ }^{4}$.

Los materiales selectos recuperados fueron depositados en dos sucesivas entregas -en noviembre de 2004 y septiembre de 2006- en el Museo de Ciudad Real por los arqueólogos responsables del hallazgo.

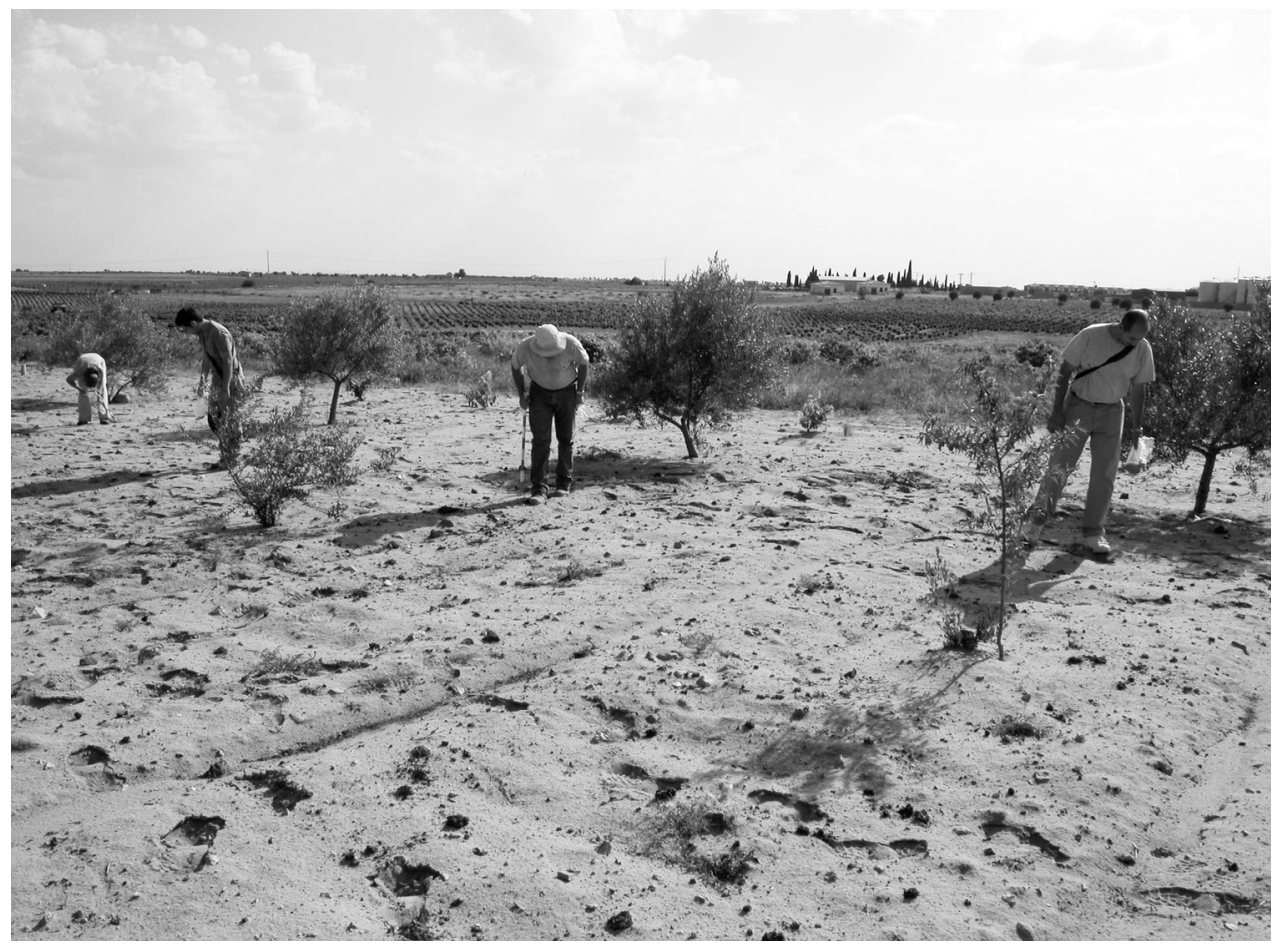

Fig. 1. Equipo de arqueólogos aplicando prospección intensiva de cobertura total en Los Parrales.

${ }^{4}$ Carta arqueológica ejecutada por el equipo de ANTHROPOS, S.L. y financiada por la Asociación de Municipios «Alto Guadiana-Mancha», la Junta de Comunidades de Castilla-La Mancha y el Ayuntamiento de Arenas de San Juan. 
Entre esas dos entregas —en junio de 2006- se registró en el Museo de Ciudad Real la entrada de un nuevo depósito de materiales procedentes del mismo lugar. Estos últimos objetos fueron recogidos del yacimiento por alguien indeterminado, probablemente a lo largo de mucho tiempo. En estos últimos dos años no hemos apreciado en el lugar la existencia de excavaciones clandestinas. Por su parte, los propietarios de las parcelas aseguran no haber visto a buscadores merodeando en sus tierras.

\section{DESCRIPCIÓN DE LA COLECCIÓN}

El material arqueológico de Los Parrales se ha encontrado disperso tanto en la parte más elevada de la loma como sobre alguna de sus laderas, en una superficie aproximada de 1,65 hectáreas. El terreno ha sido roturado, lo que ha propiciado la dispersión y fragmentación de las piezas.

En el momento de escribir este artículo sólo quedan sobre la superficie del yacimiento materiales arqueológicos no selectos.

Todas las piezas de relevancia histórica han sido recogidas y depositadas en el Museo de Ciudad Real. Entre ellas están:

- 1 afilador de pizarra, que no es piedra natural del lugar (fig. 1).

-1 escoria, que evidencia cierta actividad metalúrgica local.

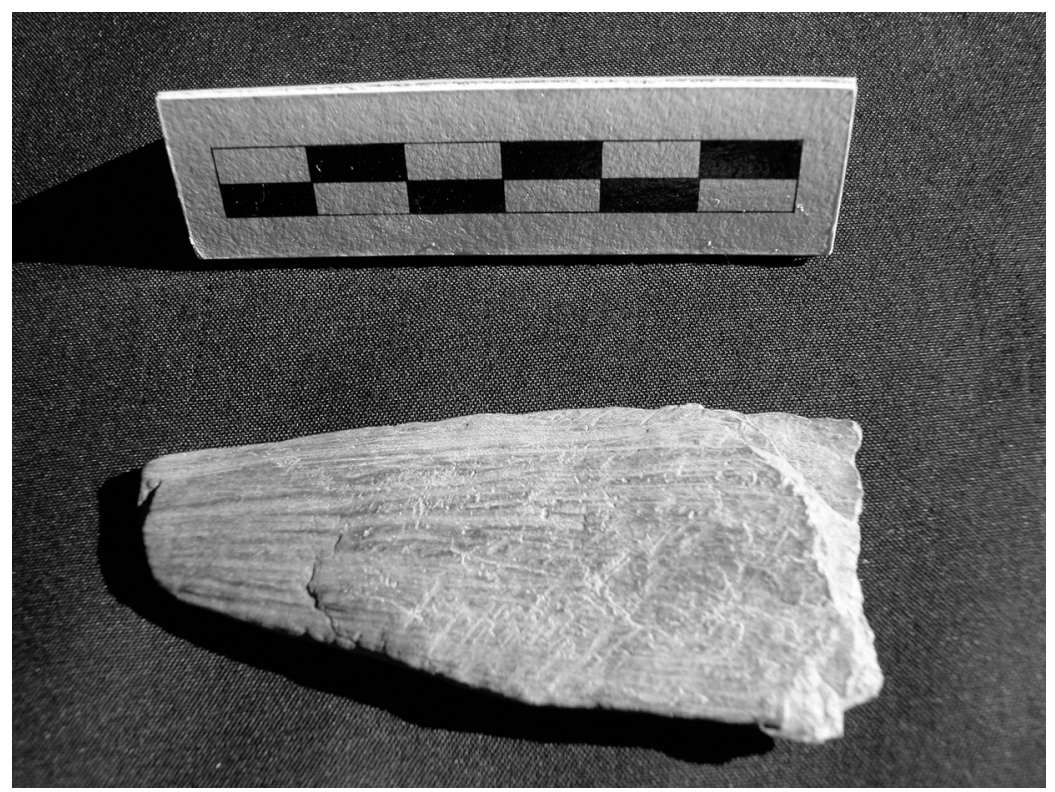

Fig. 2. Afilador de pizarra. 
- 1 fragmento de hematites rojo, apto para el bruñido de metales.

- 5 laminitas de sílex (fig. 9.6-8). Parece claro que el sílex fue materia prima lítica de uso preferente, apreciándose mayoritariamente artefactos sin retoque. Entre ellos predominan las lascas simples. Este dato indica que estas piezas eran usadas en acciones que requerían útiles poco elaborados, pero de filos vivos.

- Varios pequeños bordes rectos o almendrados, además de sendos galbos (uno de ellos con mamelón). Los fragmentos son de cerámica elaborada a mano, desgrasantes finos y cocción mayoritariamente reductora.

- 290 colgantes fabricados con hueso y dientes de forma mayoritaria, aunque no es descartable que alguno se haya elaborado sobre concha. El $85 \%$ de las cuentas están completas, sin fractura alguna. Sobre ellas nos detendremos más adelante.

- Varios restos de conchas de diversas especies. Las hemos encontrado importadas, de procedencia marina -es el caso de un pectínido (probable Pecten máximus, (fig. 6; fig. 2) y de una chamalea-, pero también autóctonas - como la dulceacuícola Potomida littoralis-.

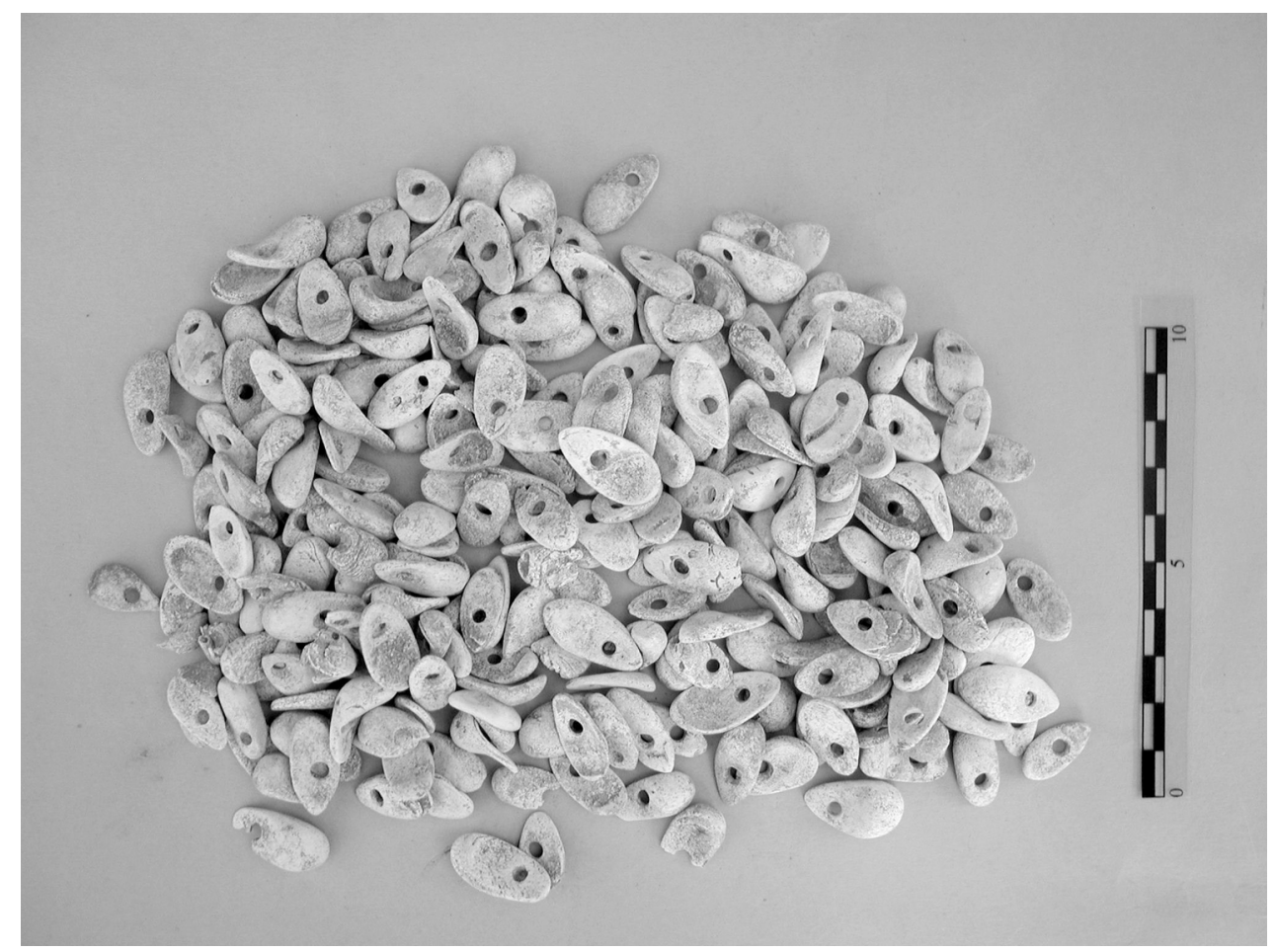

Fig. 3. Colección de cuentas procedente de Los Parrales. 


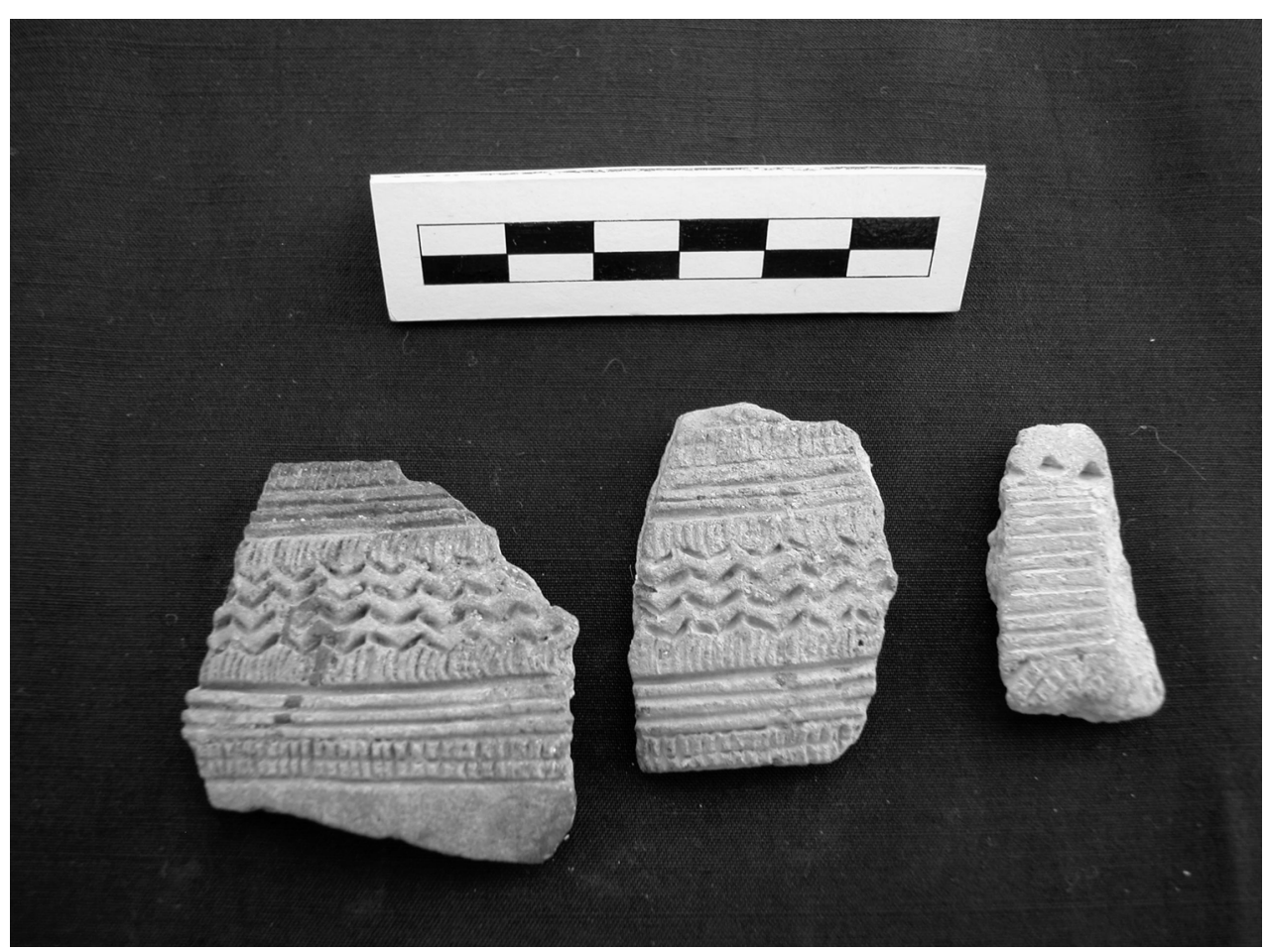

Fig. 4. Cerámica campaniforme del estilo Ciempozuelos procedente de Los Parrales.

- Tres fragmentos de cerámica campaniforme del estilo «Ciempozuelos», con decoración incisa ${ }^{5}$.

Dos son galbos cuyos motivos decorativos -zigs/zags enmarcados en franjas horizontales y paralelas separadas por espacios lisos- revelan que, a pesar de no haberse encontrado juntos, proceden probablemente de una misma pieza (fig. 3 y 4). El tercer fragmento es un borde exvasado con decoración de entramado reticulado oblicua al interior y en bandas horizontales entre frisos de triángulos (encima) y franjas oblicuas (debajo) al exterior (fig. 5). Este fragmento, susceptible de ser incluido dentro de lo que algunos autores denominan «Grupo Dornajos», puede proceder de una fuente de probable utilización doméstica, si bien pudo desarrollar algún papel en actividades rituales desarrolladas en este ámbito (GarridoPena, R., 2000: 94).

5 Tradicionalmente la decoración a la que nos referimos ha sido considerada incisa -esto es, ejecutada con un instrumento punzante que se desliza sobre la superficie de la arcilla blanda-. No conviene olvidar las interesantes sugerencias acerca de la incisión/impresión realizadas por J. M. Rojas (cit. por Garrido-Pena, 2000: 108). El carácter de impreso las cerámicas campaniformes supuestamente incisas respondería en muchos casos a la sucesiva impresión con un instrumento corto (Cardium, por ejemplo) de tramos sucesivos, que llegan a conformar las líneas que recorren el perímetro del vaso. 
Recordemos que las cerámicas campaniformes fueron apreciados bienes de lujo que formaban parte —además de los botones de perforación en « $V$ », los brazaletes de arquero o ciertos elementos metálicos (armas y adornos) - del «equipo campaniforme»: un «kit» de elementos dotados de fuerte valor simbólico destinados a revelar la dignidad y relevancia social de su poseedor. Se considera que las cerámicas campaniformes fueron recipientes cargados de significación, empleados para el consumo de una bebida especial, probablemente alcohólica. Algunos autores han destacado la importancia del control sobre el consumo de bebidas alcohólicas en diferentes sociedades, de forma especial en aquellas que carecieron de instituciones políticas y requirieron de sus dirigentes la creación de un cuerpo de clientes que les garantizasen el éxito en las luchas por el poder. Esa fidelidad se conseguía a través de actos como las fiestas del trabajo, de hospitalidad o ciertos comportamientos rituales. Existen numerosas referencias al respecto procedentes de muy distintas religiones, culturas y partes del mundo, tanto actuales como pasadas (Dumezil, G., 1997).

\section{ENTORNO GEOGRÁFICO}

El yacimiento se halla sobre una suave loma de arenas próxima al cauce del río Cigüela, en un espacio abierto y carente de defensas naturales. El lugar, en el

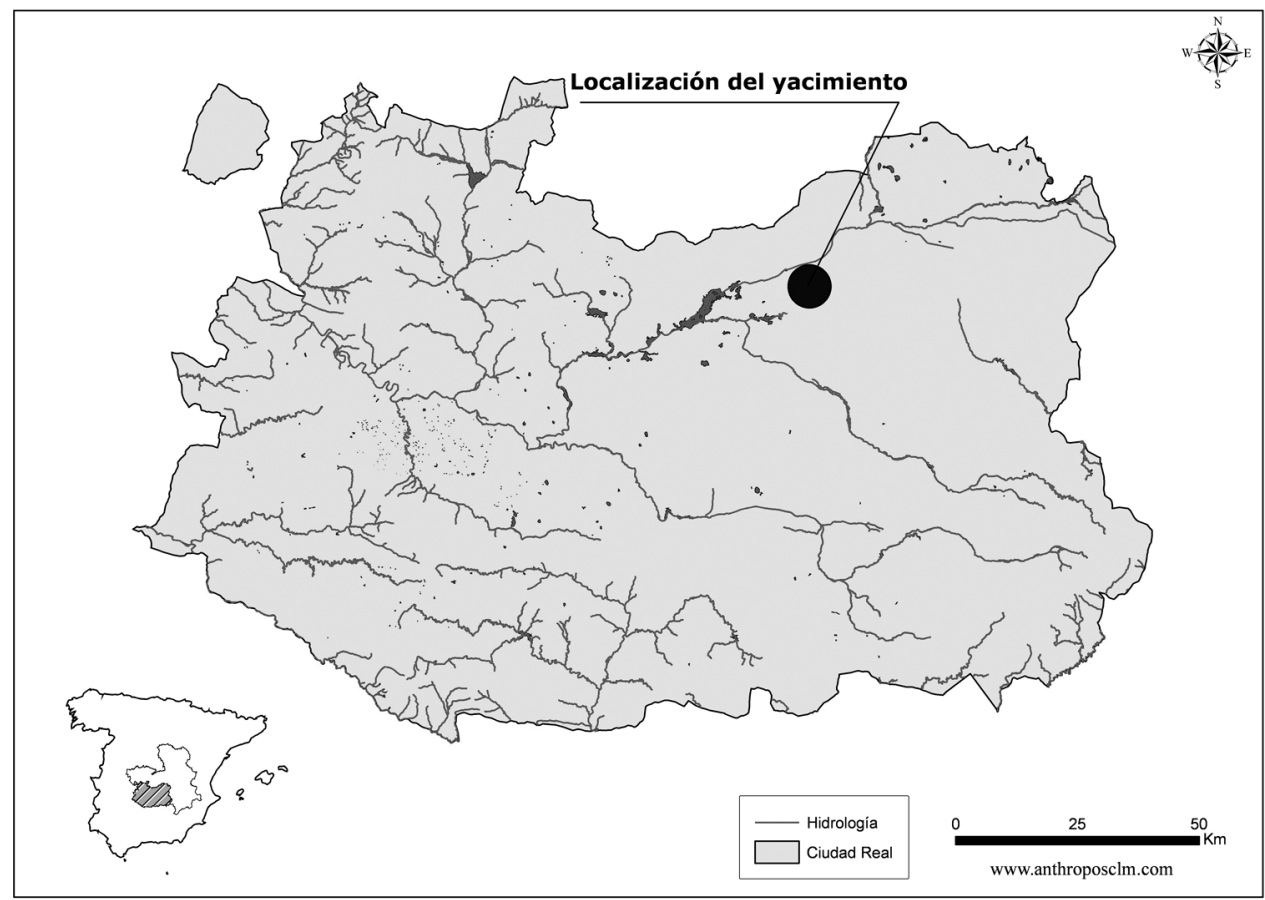

Fig. 5. Localización geográfica de Los Parrales. 
que se encuentran en superficie abundantes restos malacológicos, domina estratégicamente tanto la vega del mencionado río como sus alrededores, un territorio predominantemente llano.

En la actualidad son terrenos destinados a la explotación agraria de cultivos de secano.

El río ha generado a lo largo del Cuaternario una serie de depósitos aluviales conocidos como llanuras de inundación, en los cuales el cauce apenas ha podido encajarse.

A una distancia relativamente corta de esa llanura de inundación, fundiéndose en determinados tramos con ella, los materiales que componen el terreno -y sobre los que se ubica el yacimiento- están integrados por finas arenas silíceas (procedentes de sedimentación fluvial), calizas y margosas ${ }^{6}$, que se han venido a llamar mantos eólicos del Holoceno o paleodunas, indistintamente. Esta última denominación alude al hecho de que se trata de una clase de suelo formada en épocas en las que se produjeron cambios muy bruscos e intensos de temperatura, alternándose los años muy fríos con otros muy calurosos. Fue aquélla una dinámica frecuente durante las glaciaciones y los deshielos del Cuaternario. La influencia del viento provocó la acumulación de materiales finos en dunas, hoy ya inactivas pero aún claramente apreciables y capaces de imprimir una fuerte personalidad al paisaje.

De esa forma surgieron las arenas del entorno de Arenas de San Juan. Hoy forman paleosuelos que, como elementos geológicos o geomorfológicos de interés científico, se incluyen en el Anejo 1 de la Ley 9/1999 de 26 de mayo de Conservación de la Naturaleza de Castilla-La Mancha, que establece el Catálogo de hábitats y elementos geomorfológicos de protección especial de Castilla La Mancha.

\section{LOS COLGANTES: CARACTERIZACIÓN, CAUSAS DE DETERIORO, ESTADO DE CONSERVACIÓN Y TRATAMIENTO DE RESTAURACIÓN}

\subsection{Caracterización}

Las medidas de los colgantes son variadas y oscilan en longitud entre $1,5 \mathrm{y}$ $2,4 \mathrm{~cm}$.; entre 0,8 y $1,2 \mathrm{~cm}$. para su anchura; y 0,35 y $0.9 \mathrm{~cm}$. respecto al grosor. Su peso varía entre 0,36 y 1,78 gr. En la figura 8 representamos una selección variada representativa de su diversidad: una de las cuentas más cortas (n. $\left.{ }^{\circ} 7\right)$, una de las largas, planas y delgadas (.$\left.^{\circ} 4\right)$, una con dos orificios (n. $\left.{ }^{\circ} 3\right)$, otra rota $\left(\mathrm{n} .{ }^{\circ} 6\right)$, etc.

${ }^{6}$ En el mapa 61-200 del Instituto Geológico y Minero de España se citan calizas, margas y arenas del Mioceno en la zona. 


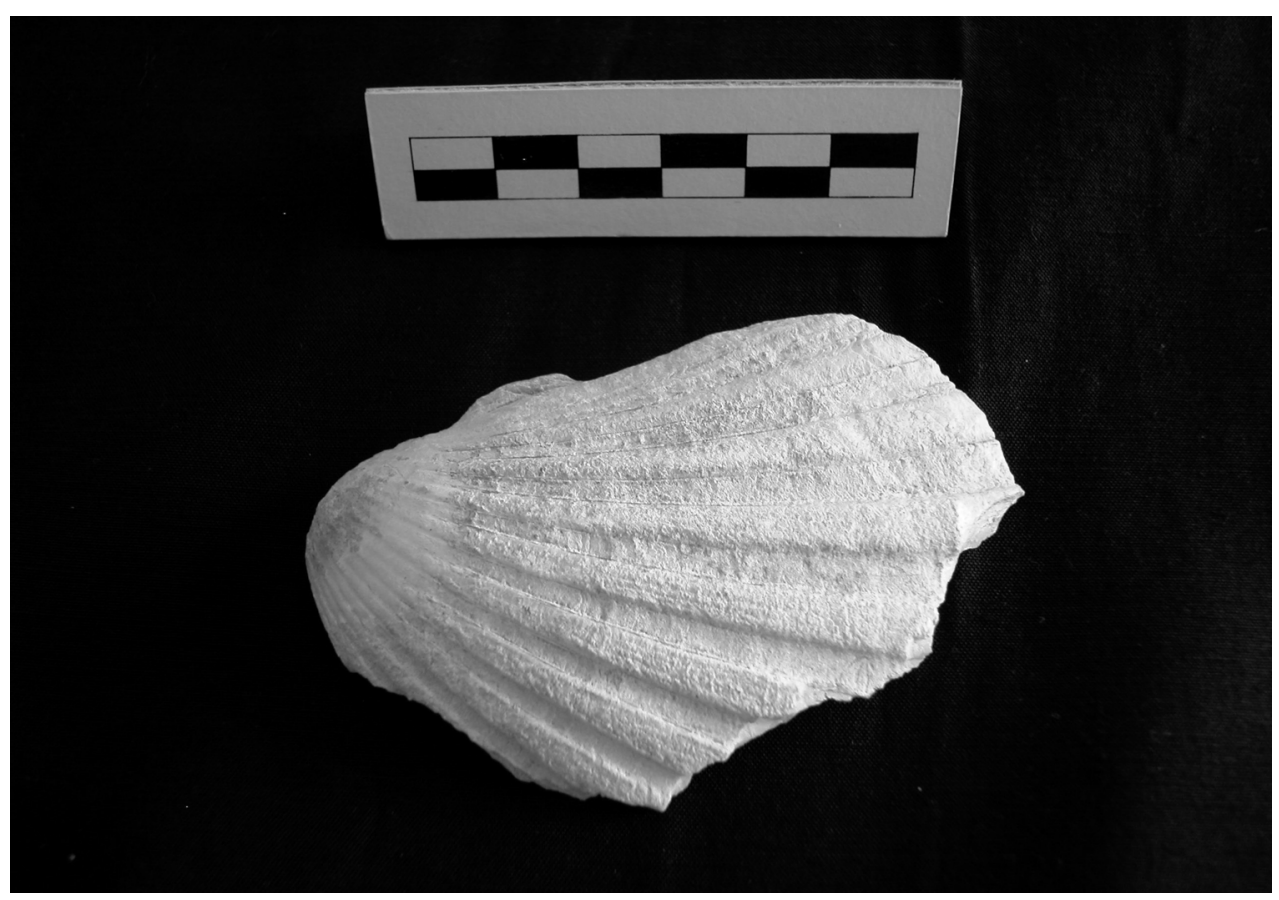

Fig. 6. Bivalvo marino Pecten.

Para verificar su composición se ha practicado a una de las piezas una prueba a la gota, con ácido nítrico diluido al $15 \%$ en agua. Observada la reacción bajo lupa binocular se ha confirmado la presencia abundante de carbonato cálcico.

Aunque es posible que alguna se fabricase con caliza o concha, la disposición de las trabéculas y la escultura apreciable en las piezas al microscopio indican que mayoritariamente fueron elaboradas con hueso y, en menor medida, a partir de dientes. La materia prima debe proceder de ovicápridos, suidos o cérvidos, pero éste extremo no podrá verificarse hasta la realización de análisis de ADN.

La utilización de conchas, dientes y hueso como materia prima para la elaboración de objetos durante la Prehistoria es un fenómeno ampliamente difundido. Glycymeris, por ejemplo, es un bivalvo liso que se usó a lo largo del Neolítico para la fabricación de cucharas y para decorar cerámicas mediante impresión (Pascual, J.L., 1998: 215).

\subsection{Forma de trabajo o manufactura}

Las cuentas corresponden a piezas recortadas y pulidas para suavizar las aristas y conseguir el aspecto ovalado en todas ellas. 


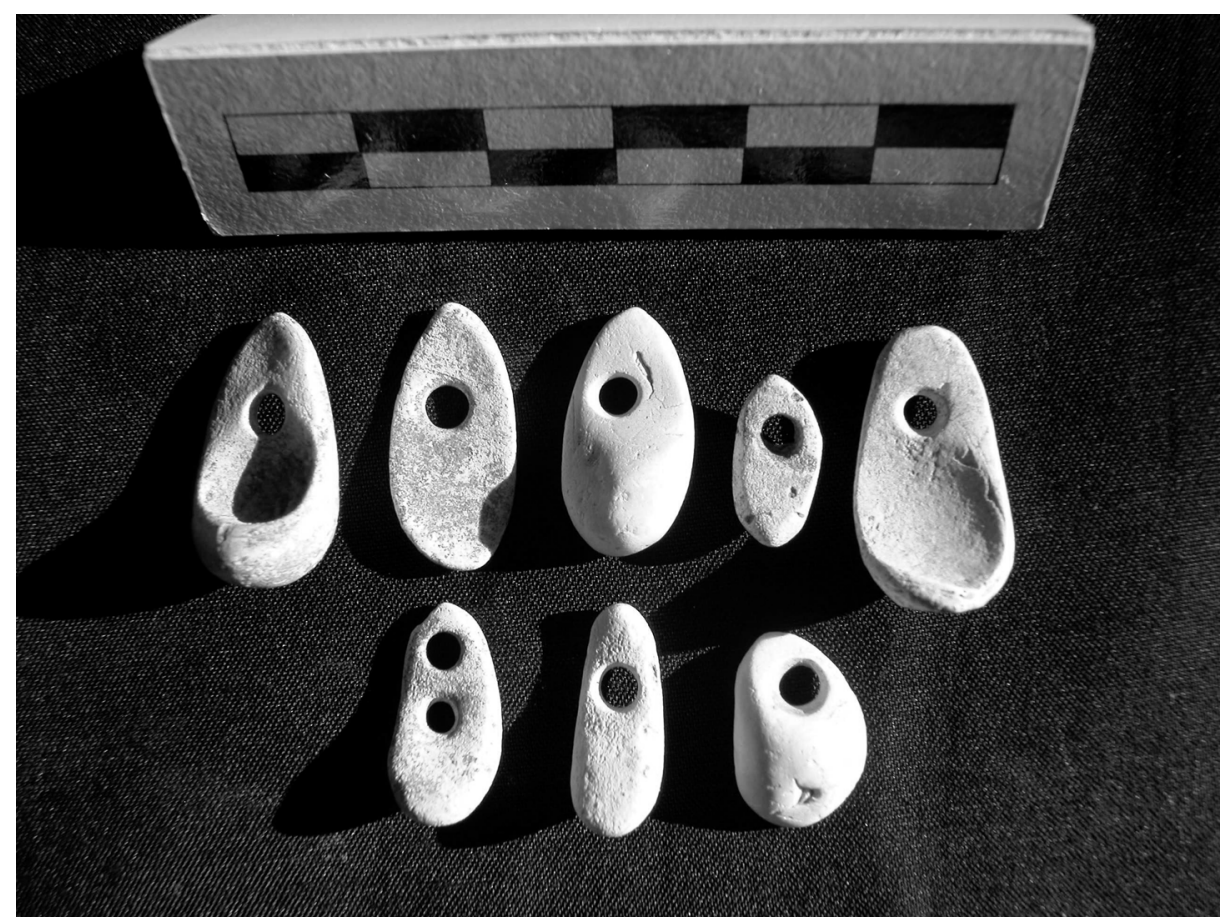

Fig. 7. Variabilidad en los tipos de las cuentas.

El orificio de engarce suele practicarse por el anverso, apreciándose la huella de alguna clase de trépano rotador marcando un cono inverso muy acusado en el orificio, que se presenta plano en el reverso. Algunas excepciones muestran un cono menos acusado; otras, practicado de atrás hacia delante; e, incluso, rematado por ambas caras, presentando conos encontrados. Suele estar situado en la parte superior de la cuenta, en la zona más delgada y estrecha del óvalo, para acentuar la función de colgante. Existe alguna excepción a ésto, en el caso de orificios más centrados. Quizás evitaban así, con sabiduría, la fragilidad de determinadas secciones de la materia prima, más vulnerables por su naturaleza delgada y estratificada. Hay una pieza que presenta dos orificios, tal vez fabricada para cumplir una función de cierre con doble pasada de hilo de engarce.

El trabajo de pulimento exterior llega a ser preciosísimo, lo que se puede percibir en algunas piezas que mantienen el aspecto brillante que en origen debieron adquirir todas, como estimado objeto de adorno. Cabe suponer una cierta intencionalidad en la desigualdad longitudinal de las piezas, que se engarzarían siguiendo ritmos simétricos o alternos, según la creatividad del operador.

La presencia de materia prima y objetos manufacturados en superficie mueve a considerar a éste un lugar de recogida y acumulación de materia prima, así como de producción. 
Las gentes calcolíticas aquí instaladas encontraron en Los Parrales conchas para elaborar adornos personales, a las que sumaron otras traídas de ámbitos litorales. Utilizando estos soportes, además de dientes y huesos captados de fauna doméstica o salvaje de la zona, crearon un taller artesanal en el que fueron manufacturados colgantes ovales.

Por el momento, a falta de realizar estudios de detalle, es preciso considerar esta hipótesis como preliminar.

\subsection{Causas del deterioro}

Los colgantes del yacimiento de Los Parrales muestran, en general, buen estado de conservación. Ello permite su análisis y estudio científico, al tiempo que asegura su función didáctica y expositiva como elemento musealizable.

No obstante, es importante reconocer y definir los problemas de deterioro que presentan, así como las causas que los provocan, a fin de establecer los mecanismos, tratamientos y parámetros más adecuados para su conservación a largo plazo.

Con este fin se han analizado la estructura física y la composición química de la materia prima con que han sido elaborados, la técnica de fabricación de los mismos y el medioambiente en que han permanecido hasta su descubrimiento, considerando en qué medida cada uno de estos aspectos puede haber influido en el estado de conservación de los materiales.

Cualquiera que sea la materia prima empleada en la fabricación de los colgantes - hueso, diente o concha - es importante señalar que se trata de materiales en los que se combinan materia orgánica (oseína, dentina o conquiolina) con inorgánica (normalmente carbonato cálcico), para formar estructuras diferentes. Unos y otros son susceptibles de deterioro diferenciado, bien por ácido (parte inorgánica) o por exceso de humedad, biodeterioro, etc. (parte orgánica). Por lo tanto, su conservación dependerá de la estructura física y química concreta de la pieza, así como de las condiciones del medio en que se encuentran.

Por lo que respecta al sustrato arqueológico, ya se ha señalado que las cuentas se localizaron en un suelo de arenas finas, cuyo análisis puede ayudar a comprender el estado de conservación de estos materiales.

Se trata de un suelo poroso y aireado que, en presencia de humedad, se empapa y se vuelve impermeable. Podemos suponer, por tanto, que permite el desarrollo de bacterias aerobias y anaerobias, capaces de provocar el deterioro de la fracción orgánica de estas piezas, fundamentalmente. El pH del suelo es ligeramente básico, no afectando de forma importante a los colgantes.

El tercer factor a tener en cuenta para el análisis del estado de conservación del material hallado en Los Parrales es la técnica empleada para su fabricación, so- 


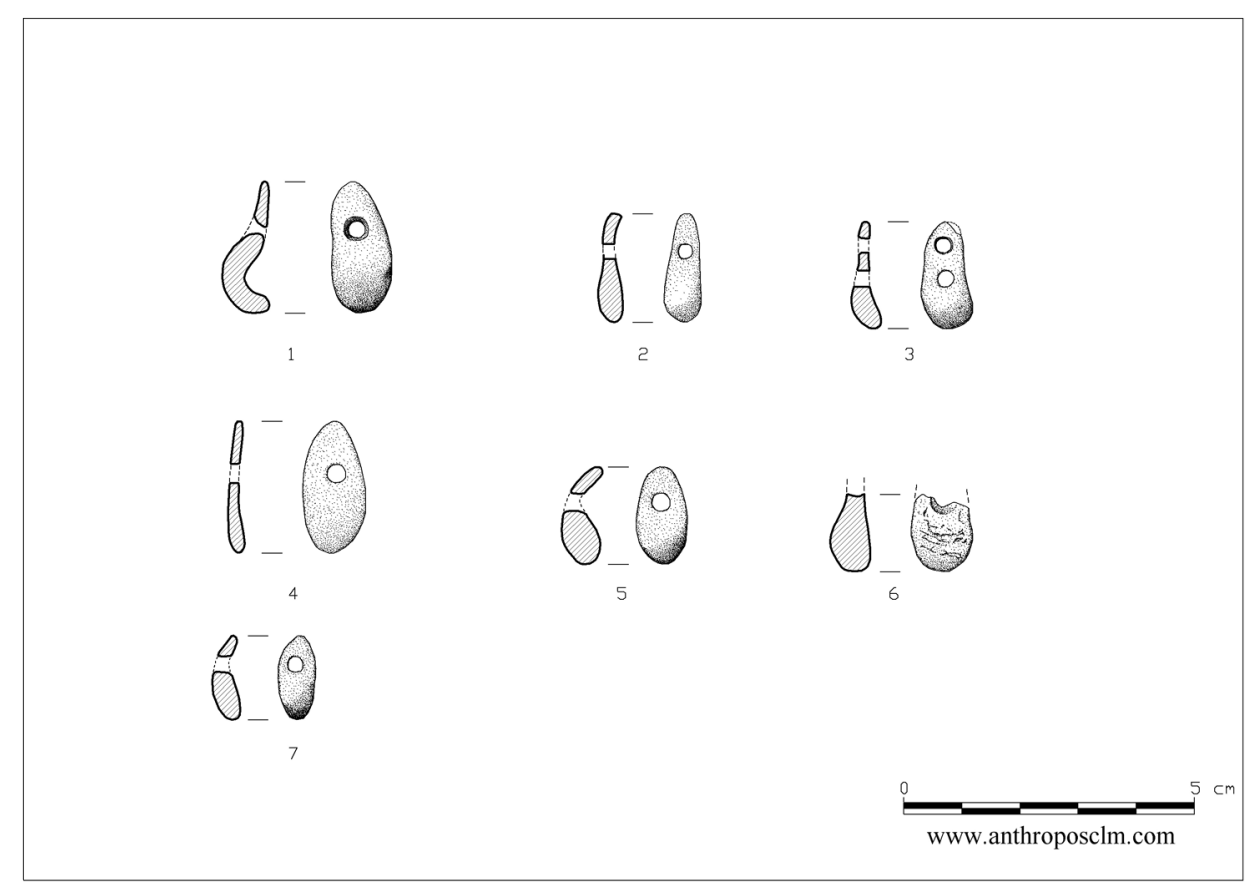

Fig. 8. Selección de cuentas.

bre la que ya hemos expuesto algunas consideraciones en apartados anteriores. El pulimento y abrasión necesarios para conseguir la forma ovalada de los adornos suponen una pequeña reestructuración de los componentes de la materia prima, que puede afectar a su resistencia frente a los factores medioambientales. La forma de los colgantes y la disposición del orificio de suspensión permiten pensar que se persiguió la definición de una forma mixta plano/convexa en el perfil de las piezas, que es el que en realidad se expondría si pensamos en las mismas engarzadas como collar.

\subsection{Estado de conservación}

La mayor parte de las piezas que forman el conjunto que ahora analizamos están completas y sin fragmentar. La degradación del elemento orgánico como consecuencia de procesos de biodeterioro provoca la aparición de los siguientes problemas de conservación:

- Depósito de tierra y suciedad superficial que, dado el sustrato en que se han encontrado, está constituida fundamentalmente por arcillas.

- Porosidad y aumento de la exposición a los nuevos agentes de deterioro mecánicos y químicos con los que se enfrentan las piezas una vez extraí- 
das de su medioambiente arqueológico: manipulación, cambios de humedad y temperatura, agentes atmosféricos dañinos, etc.

- Exfoliación. Tierra y arcillas del sustrato en el que se encontraban las piezas ocupan parte de las capas de materia prima que se han perdido. Esos elementos son mucho más inestables que los originales, y diferentes de ellos en cuanto a volumen y propiedades químicas o físicas. El aumento de tamaño de las interfases supone el desplazamiento de las capas originales, con la consiguiente pérdida de cohesión, deformación y posible fragmentación que podría producirse, normalmente, en capas paralelas al eje longitudinal de los colgantes.

- Fragmentación y pérdida de material constituyente. En las piezas que examinamos la fragmentación se refleja sobre todo en la parte más gruesa de las mismas. En ella los componentes originales presentan diferente orientación en cada una de las capas que conforman el cuerpo, por lo que la anisotropía es más intensa y el deterioro más acusado, mientras que son menos los colgantes en nuestro conjunto que están fracturados por la parte superior -en principio más fina y vulnerable, especialmente si se toma en cuenta que en ella se practica la perforación que permite su suspensión-.

\subsection{Tratamiento de conservación-restauración}

La finalidad de todo tratamiento de conservación-restauración no es otra que la de asegurar la conservación y el mantenimiento de la realidad física de los objetos para que éstos cumplan su función de transmitir la información histórica que contienen.

En el caso de los materiales arqueológicos, la importancia de esta función se acentúa, pues son los ellos los únicos elementos de que disponemos para conocer diversos períodos de nuestra Pre y Protohistoria.

Dado el estado de conservación de los colgantes de Arenas de San Juan, el objetivo de los tratamientos a que serán sometidos no es otro que devolverles la estabilidad $\mathrm{y}$, al menos, parte de las propiedades mecánicas que han perdido como consecuencia de la degradación de la materia orgánica cementante, así como asegurar su protección y resistencia frente a posibles nuevas agresiones medioambientales. Se busca la mínima intervención que permita una mayor estabilidad. Para ello, se llevarán a cabo las siguientes actuaciones:

- Limpieza y eliminación de los depósitos arcillosos superficiales e internos, por medios mecánicos (pincel de cerda corta), apoyados puntualmente en disolventes químicos suaves (agua desmineralizada, etanol y acetona), que faciliten la limpieza eliminando suciedad. 


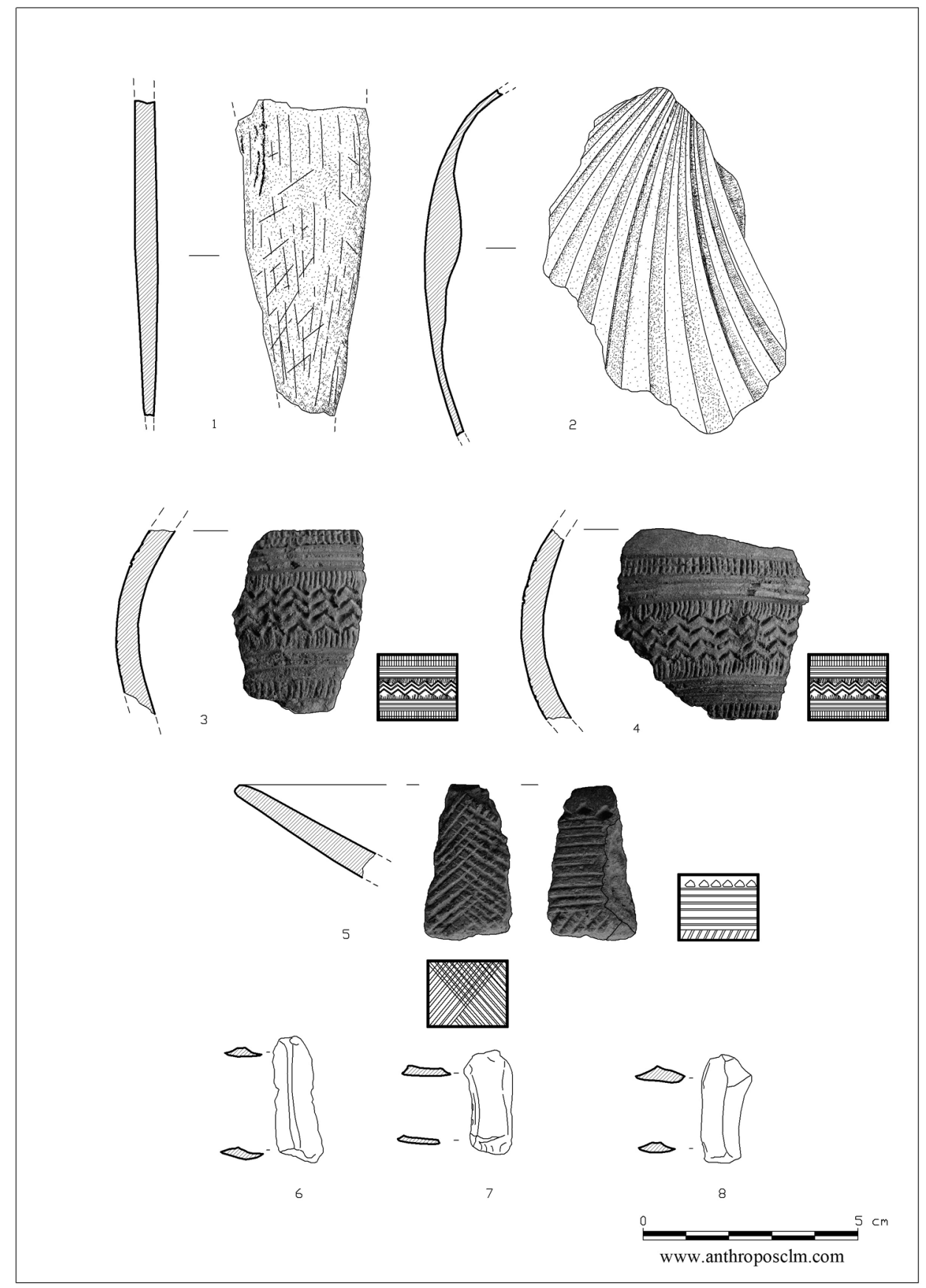

Fig.9. Materiales arqueológicos procedentes de Los Parrales. 
- Consolidación por inmersión o aplicación de resinas acrílicas preparadas en disolventes de mediana volatilizad. Se evita así, por un lado, la fracturación consecuencia de un secado excesivamente rápido y, por otro, la formación de una capa superficial que varíe el aspecto de los colgantes.

Junto a la resina se aplicarán, en porcentajes del $5 \%$, productos biocidas que eviten el desarrollo de procesos de deterioro biológicos.

El embalaje en el que se guardan es inerte químicamente y físicamente protector. Las piezas se disponen en bolsas con espuma de protección, debidamente identificadas y se han introducido en cajas herméticas con gel de sílice que asegure la absorción de humedad.

Tanto en almacenamiento como en exposición, las condiciones ambientales se limitarán al $40 \%$ de humedad relativa y $20^{\circ} \mathrm{C}$ de temperatura, evitando que sean expuestas a radiaciones ultravioletas e infrarrojos, restringiendo la iluminación entre 150 y 300 luxes.

\section{CONTEXTO ARQUEOLÓGICO}

El estudio acerca de las primeras comunidades metalúrgicas de la Cuenca Alta del Guadiana está aún pendiente de desarrollo. A la ausencia de proyectos de investigación significados se une la escasez de los datos publicados.

Hace varias décadas fueron dados a conocer los resultados de los primeros estudios para la época calcolítica en esta zona, fruto del análisis de diversas colecciones antiguas - como la de El Pico, en Campo de Criptana (Estavillo, D., 1950: 37); o la de la Vega de los Morales, en Aldea del Rey (Vallespí, E. et al., 1985)—. También de algunas prospecciones que permitieron detectar nuevos asentamientos de ese período en la Comarca de Almadén (López Fernández, F. J. y Blanco, A., 1993: 91), en la Vega del Jabalón (Blanco, 1985), en el Campo de Montiel (Poyato, C. y Espadas, J. J., 1994; Pérez, J., 1985: 209) o en La Mancha noroccidental (Ruiz Taboada, A., 1998: 157 y ss.).

El conocimiento sobre el Calcolítico en la provincia de Ciudad Real se vio aumentado con las investigaciones sobre las pinturas rupestres esquemáticas del Valle de Alcudia, Sierra Morena y Sierra Madrona (Caballero, A., 1983: 519; Fernández Rodríguez, M., 2003: 59).

Pero la información más relevante procede del muy reducido número de yacimientos arqueológicos que han sido objeto de excavación sistemática: la necrópolis del Cerro Ortega, en Villanueva de la Fuente (Barrio, C. y Maquedano, R., 2000); el poblado en altura de El Castellón, en Villanueva de los Infantes (Espadas, J. J., 1986 y 1987; Poyato, C. y Espadas, J. J., 1989 y 1994); la necrópolis del Abrigo de Cueva Maturras, en Argamasilla de Alba (Gutiérrez, C. et al., 2000) o el asentamiento de Huerta Plaza, en Poblete (Rojas, J. M. y Gómez, A., 2000). En Cerro Or- 
tega, Cueva Maturras y Huerta Plaza se han documentado diferentes ritos de inhumación, en ocasiones con notable ajuar asociado. Los dos últimos yacimientos mencionados han permitido concluir a sus investigadores sobre la existencia de contactos evidentes en esta época entre nuestra zona y el Sudoeste peninsular, a través del río Guadiana. Ello podría resultar de gran interés para la distribución de las cuentas fabricadas en Los Parrales. El Castellón, por otro lado, es el único yacimiento calcolítico en altura excavado de forma sistemática en este territorio.

Desgraciadamente, estas honrosas y de calidad excepciones han visto limitadas sus actuaciones a unas pocas campañas, sin que ninguno de los casos goce de continuidad en la actualidad.

El ingente volumen de información generado en 2004 y 2005 a partir de la elaboración de la Carta Arqueológica de la provincia de Ciudad Real no ha servido hasta el momento para proporcionar interpretaciones territoriales globales. Se echa en falta la promoción de estudios de síntesis y de interpretación territorial, a pesar de que la Disciplina ha recordado reiteradamente que la Arqueología carece de sentido si no es en el marco de un proceso de investigación científica dirigido a crear conocimiento histórico, y que no hay investigación científica posible sin publicación y presentación de los resultados.

La obligación de cualquier arqueólogo es publicar sus investigaciones y hacer Historia. Y la de la Administración competente la de tomar medidas cuando ello no sucede (Querol, A. y Martínez, B., 1996: 37; Guiral, C. y Zarzalejos, M., 2003: 57; Fernández Martínez, V., 2006: 72).

En el momento presente las mayores expectativas para profundizar en el conocimiento del Calcolítico en el Alto Guadiana proceden del estudio de los niveles inferiores de la Motilla del Azuer (Daimiel) —objeto de excavación sistemática desde la década de los ochenta por parte del equipo dirigido por los profesores Nájera y Molina - o, principalmente, de la aplicación de la legislación vigente en las numerosas intervenciones de seguimiento y evaluación para determinar el impacto ambiental de las obras públicas.

A este respecto queremos traer a colación, a modo de breve ejemplo, los yacimientos calcolíticos detectados por nuestro equipo en el término municipal de Ciudad Real con motivo de la vigilancia ambiental aplicada a la construcción de su aeropuerto. Los enclaves aequeológicos de La Halconera, Milagros y Alto Valle I agrupan hasta una decena de pequeñas instalaciones con estratigrafías poco potentes, arrasadas por el paso del tiempo y las labores agrícolas, tal y como se pudo comprobar mediante la excavación de sondeos arqueológicos en los yacimientos detectados mediante prospección de superficie. Los casos mencionados constituyen un poblamiento continuado a lo largo de la vega del Jabalón, pero disperso. Allí se construyeron cabañas sobre los pequeños espolones que tiene la terraza meridional de este río. Además de estos asentamientos, que como hemos señalado son dispersos y fueron levantados sobre suave altura, se registró la existencia 
de otro mayor en llano, en zona de vega pero ligeramente retirado del área de encharcamiento del río. Fue denominado El Valle. Mientras que en los tres primeros lugares citados el material arqueológico es muy escaso, en éste último se encuentra en mayor cantidad. A la presencia de galbos de cerámica elaborada a mano - algunos con mamelones-y bordes almendrados de platos hay que añadir fragmentos de molinos de mano, cuchillos de sílex o de hachas de piedra pulida. El contacto visual era posible entre los diferentes lugares mencionados. En ningún caso se aprecia la existencia de defensas naturales 0 artificiales; son sitios fácilmente accesibles y vulnerables.

Este patrón de asentamiento - gran poblado en llano al que se vinculan otras instalaciones menores que sirvieron para controlar las vías de paso- es conocido y está bien estudiado en otros sectores de la cuenca del Guadiana, como es su tramo medio (Hurtado, V., 1984: 51 y ss.).

Los datos que aportamos con esta breve noticia nos resultan útiles al desarrollo del presente trabajo porque el yacimiento en el que nos detendremos - Los $\mathrm{Pa}$ rrales-, como sucede en el caso de La Halconera, Milagros o Alto Valle I, se localiza sobre una suave altura que permite el control visual de la vega de un gran afluente del Guadiana. En todos los casos estamos ante asentamientos que no son grandes, en espacios abiertos y vulnerables, sin defensas aparentes y con escaso material en superficie. Se trata probablemente de un poblamiento disperso de cabañas endebles dispuestas a lo largo de las suaves elevaciones que jalonan la cuenca del Alto Guadiana y sus afluentes tributarios, con una base económica agrícola y ganadera de especies progresivamente más seleccionadas que, en el caso de los animales, irían con el tiempo siendo aprovechadas para nuevos fines (productos lácteos, fuerza de tiro, el arado o el carro). En el caso de Los Parrales, además, la producción de manufacturas cobró notable trascendencia.

Buena parte de estos asentamientos calcolíticos debieron empezar su ocupación durante el Neolítico Final, sin que sean detectables cambios significativos entre una y otra etapas; ni en cuanto a su organización social, ni en lo que respecta a sus modos de vida.

La introducción de la metalurgia —una de las principales características de este período para otros ámbitos peninsulares - no parece producirse en el Alto Guadiana hasta un momento avanzado del Calcolítico (en torno a finales del Tercer Milenio), en relación al fenómeno conocido con el nombre de Calcolítico Campaniforme.

La escoria encontrada en el yacimiento Los Parrales, en asociación a cerámica campaniforme, permite fechar de forma provisional el yacimiento a finales del Tercer Milenio, dentro de la cultura conocida como Calcolítico Campaniforme.

En definitiva, aunque aún falta por explicar en toda su dimensión la época calcolítica en el Alto Guadiana, existen ya sobradas evidencias de que en aquel momento ésta no fue, como se ha mantenido en ocasiones, una zona deshabitada o 


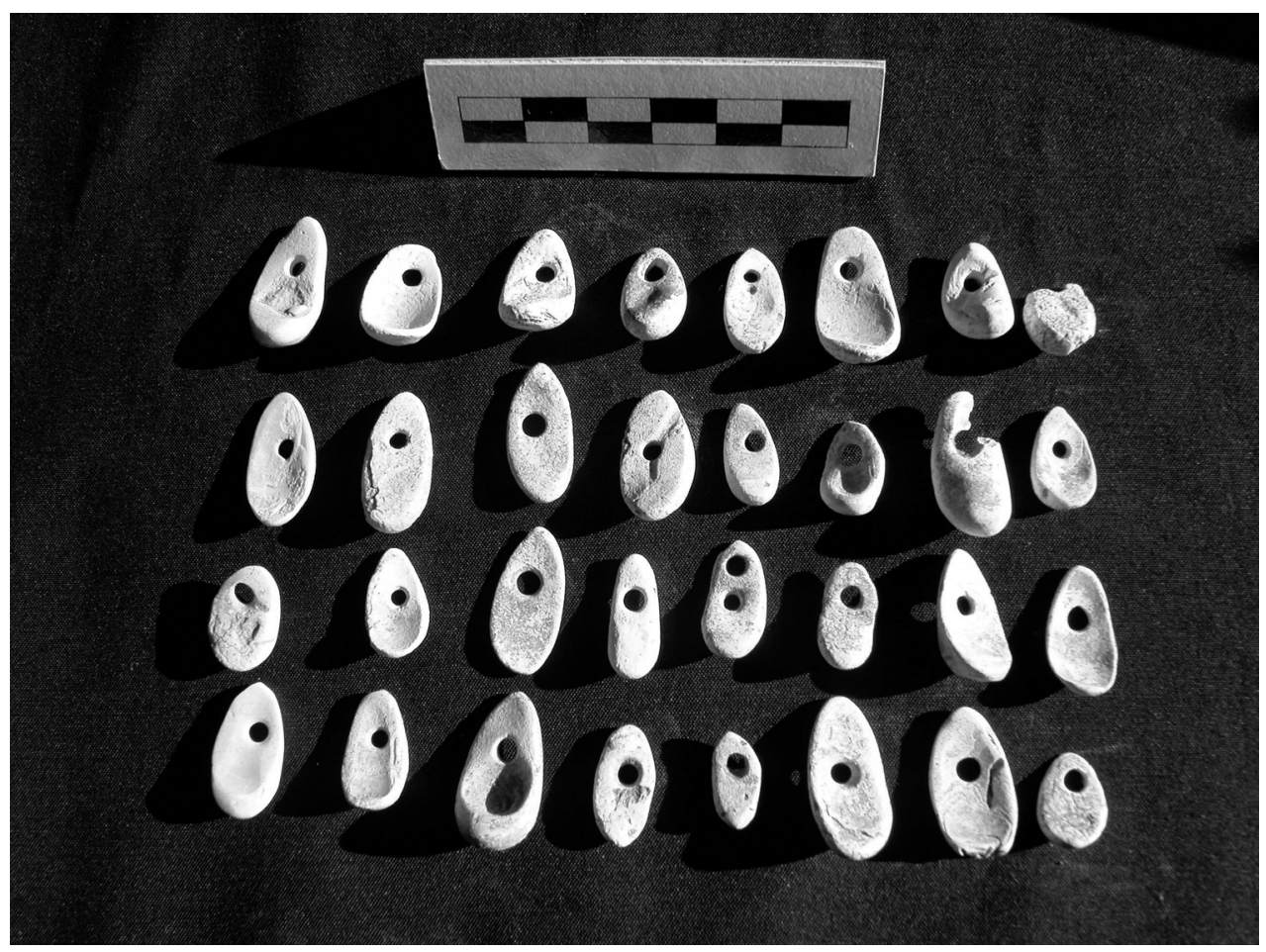

Fig. 10. Selección de cuentas.

retardataria, al margen de las influencias de otras zonas peninsulares más conocidas.

Más bien al contrario, hoy sabemos que fue centro productor de preciados objetos de adorno similares a otros que han sido encontrados en diferentes puntos de la Península Ibérica, y que bien pudieron ser distribuidos a través de ese gran corredor de gentes, ideas y mercancías que fue la cuenca del Guadiana.

\section{VALORACIÓN FINAL}

Con este trabajo damos cuenta de la existencia de un yacimiento arqueológico excepcional, localizado en un área del interior peninsular: el Alto Guadiana.

Obedece a un patrón de asentamiento sobre suave elevación que domina la vega de un río.

Debería adscribirse, pues, a la clase de instalaciones que caracterizan el Calcolítico Precampaniforme en el Alto Guadiana, según la clasificación propuesta por algunos autores (Rojas, J. M. y Gómez, A., 2000: 24). Sin embargo, presenta cerámica Campaniforme, del estilo Ciempozuelos. Además de esta clase cerámica de 
prestigio ha aportado casi trescientas cuentas similares a otras que han sido recuperadas en estratigrafías neolíticas, frecuentemente denominadas «de lágrima" y que se han visto asociadas a enterramientos en cuevas, casi siempre en áreas periféricas de la Península Ibérica. Aún así, esos otros hallazgos peninsulares no han ido más allá de unas pocas cuentas de concha para cada uno de los casos (Arribas, A., 1952; Baldeón, A. et al., 1983; Baldellou, V., 1985 y 1987; Bosch, A., 1985; Goñi, A. et al., 1999: 165; Martín, D. et al., 2002, 73-74; Pascual, J. L., 1998: 142; Siret, E. y Siret, L., 1890, Lám. 25, pieza 29; Ten, R., 1979; Teruel, M. S., 1986: 20).

Por tanto, resulta sorprendente que en el poblado calcolítico campaniforme Los Parrales se hayan encontrado 290 de ellas y en superficie, no durante un proceso de excavación arqueológica.

La inusual acumulación de esta clase de elementos en Los Parrales supone una llamada de atención acerca del papel nada intranscendente que las comunidades calcolíticas jugaron en el Alto Guadiana, del cual aún conocemos demasiado poco.

Las cuentas fueron elaboradas por estos antepasados de los castellano-manchegos de acuerdo a unos gustos estéticos y una tradición ancestrales, cuyas raíces pueden hundirse probablemente en el Paleolítico. En este sentido queremos destacar la similitud de los colgantes ovales depositados en el Museo de Ciudad Real con los caninos atrofiados de cérvidos, cuyo uso como colgante se remonta al Paleolítico Superior. Es una forma que ha llamado profundamente la atención a lo largo de la Prehistoria, siendo reproducida de forma reiterada en concha, hueso y piedra a una escala internacional por grupos neolíticos y calcolíticos, si bien no ya de forma significativa por los de la Edad del Bronce (Pascual, J.L., 1998: 144).

Poyato y Espadas se preguntaban con lucidez en la década de los noventa qué pudieron haber ofrecido al exterior los asentamientos calcolíticos del Alto Jabalón (Poyato, C. y Espadas, J. J., 1994: 60-61). En El Castellón recuperaron diversos elementos que estimaron habían sido importados: materias primas alóctonas (sílex), objetos manufacturados pulimentados (hachas, azuelas, brazaletes de arquero y esferoides), cerámicas decoradas (campaniformes y tipo Dornajos), botones de marfil de perforación en « $V$ » o cuentas de collar de ámbar. Dado que los contactos comerciales suelen ser bidireccionales, los receptores debieron haber ofrecido algo a los comerciantes en el momento del intercambio. Los investigadores mencionados apuntaron la posibilidad de que no sólo se tratase de una oferta material, planteando como activo de aquellas comunidades «su inmejorable posición estratégica considerada dentro de un macrosistema cuyas dimensiones aún se nos escapan".

Unos años después, la breve investigación desarrollada en Los Parrales permite avanzar y dar un paso firme a este respecto: en el corazón de La Mancha existió en época calcolítica un grupo de artesanos que fabricaron colgantes ovales 
destinados al adorno personal siguiendo unos patrones estilísticos y estéticos que permitían asegurar el éxito en su comercialización.

En este punto cabe recordar que la existencia de comercio entre diferentes grupos a través del Guadiana ya fue planteada por algunos autores (Delibes y Fernández Miranda, M., 1993: 186). Sin olvidar la posibilidad de contactos a través de Sierra Morena mediante antiguas rutas de trashumancia, aprovechadas en este momento como vías para el intercambio (Muñoz Amilibia, A. M., 2001: 345). Hoy sabemos que la ganadería influyó poderosamente en la distribución del poblamiento durante el Calcolítico meseteño, vinculándose muchos yacimientos con rutas ganaderas, cursos de agua y humedales o salinas (Fábregas, R. y Ruiz Gálvez, M. L., 1997: 203-4).

En definitiva, el tipo de asentamiento y el hallazgo de las cerámicas campaniformes, hematites, la escoria y las cuentas ovales de tradición neolítica son reflejo de una sociedad que transita entre el Neolítico y el Bronce de La Mancha, con personalidad propia y diferenciada de estas otras dos fases culturales.

Antes de terminar es importante plantear una reflexión nada baladí sobre la denominación de las cuentas recuperadas. Desde el presentismo es fácil introducir de forma inconsciente una carga significativa nada desdeñable, y no suficientemente

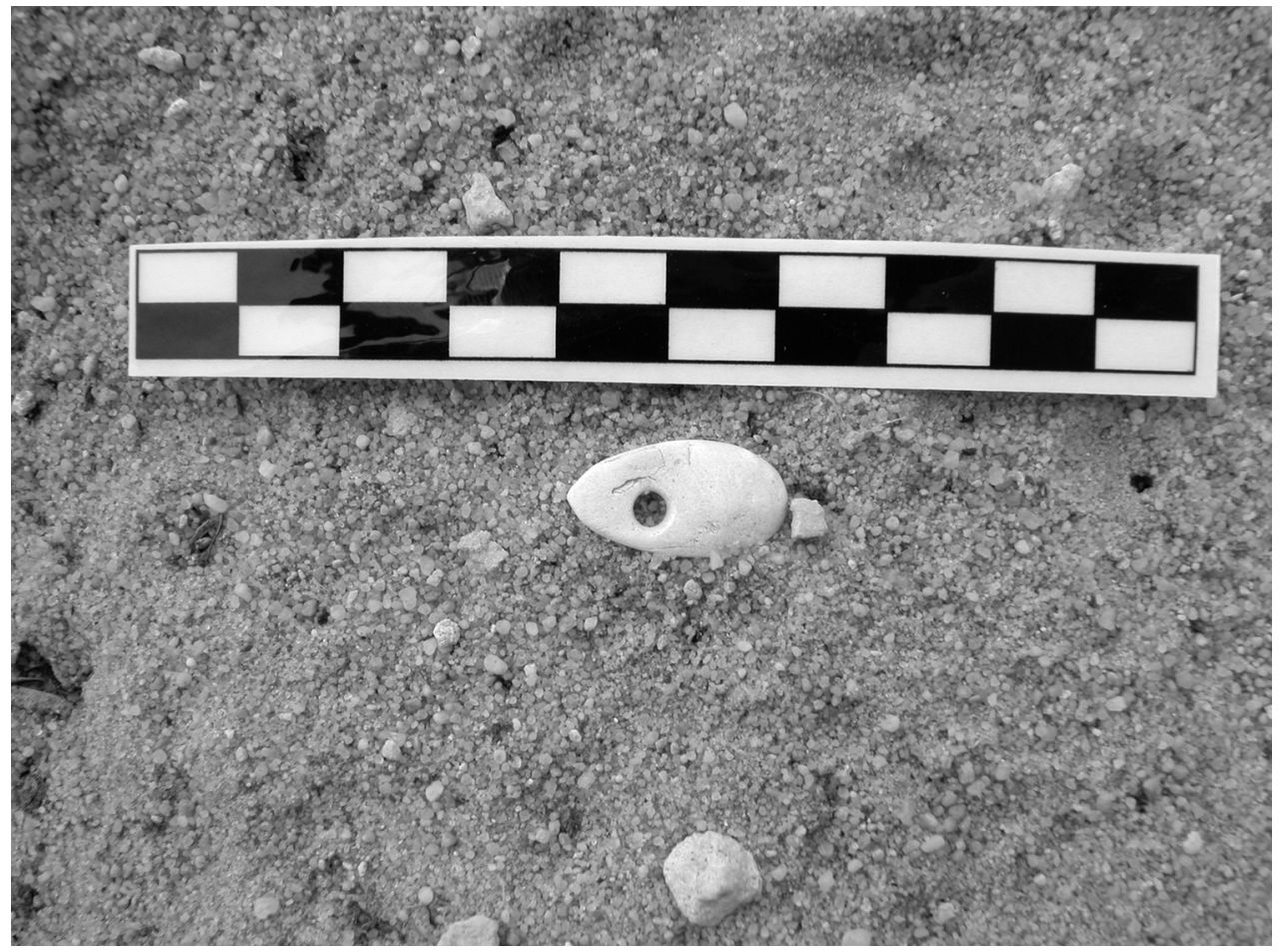

Fig. 11. Cuenta en el momento de su hallazgo. 
contrastada, mediante la utilización de expresiones como «cuentas de collar» o «adornos personales». Más aséptica resulta la de «colgantes ovales».

Lo cierto es que por el momento no podemos estar seguros de si estas cuentas fueron usadas en collares, pendientes $\mathrm{u}$ otros adornos, o como objetos para el trueque premonetal o bienes de prestigio; o, simplemente, como bisutería personal cotidiana. Pudieron haber sido usadas para cualquiera de estos fines.

Profundizar en el estudio del Calcolítico del Alto Guadiana podría esclarecer aspectos de gran interés para entender no sólo éste, sino también otros momentos históricos; por ejemplo, el papel que juega el sustrato local calcolítico en la aparición del Bronce de La Mancha.

En todo caso, la investigación en detalle del excepcional taller localizado en Los Parrales y de su entorno a buen seguro permitiría arrojar luz sobre este período de la Prehistoria del Alto Guadiana, aún insuficientemente conocido.

\section{BIBLIOGRAFÍA}

Álvaro E. de (1987): «El poblamiento calcolítico en la Meseta Sur en el origen de la metalurgia en la Península Ibérica», en Fernández Miranda, M. (dir.): El origen de la metalurgia en la Península Ibérica, vol. II, Fundación Ortega y Gasset. Madrid, pp. 16-36.

ARRIBAs, A. (1952): «El ajuar de las cuevas sepulcrales de los Blanquizares de Lébor (Murcia)», Memoria de los Museos Arqueológicos Provinciales, XIII-XIV, Madrid, pp. 78-126.

Baldeón, A., García, E., Ortiz, L. y Lobo, P. (1983): «Excavaciones en el yacimiento de Fuente Hoz (Anúcita, Alava). Informe preliminar. I campaña de excavaciones», Estudios de Arqueología Alavesa, 11, Vitoria, pp. 7-67.

Baldellou, V. (1985): «Comentario a los materiales neolíticos de la Cueva de Chaves», Bolskan n. ${ }^{\circ}$, Huesca, pp. 67-94.

- (1987): «Avance al estudio de la Espluga de la Puyascada», Bolskan, 4, Huesca, pp. 4-41.

BARNES, R. D. (1987): Zoología de los invertebrados. Interamericana. México. (4. a Edición).

BarRIO, C. y MAQuedano, R. (2000): «La necrópolis calcolítica de Cerro Ortega (Villanueva de la Fuente), en Benítez de Lugo L. (coord.): El Patrimonio arqueológico de Ciudad Real. Métodos de trabajo y actuaciones recientes, UNED (Valdepeñas, Ciudad Real), pp. 67-86.

Berducou, M. C. (coord.) (1990): La conservation en Archéologie. París.

Blanco, I. (1985): «El poblamiento de la provincia de Ciudad Real durante las Edades del Cobre y del Bronce», Universidad Abierta. Revista de Estudios Superiores a distancia, 4, UNED. Valdepeñas (Ciudad Real), pp. 23 y ss.

Blasco, M. ${ }^{a}$ C. (ed.) (1994): El Horizonte Campaniforme de la región de Madrid en el Centenario de Ciempozuelos. UAM. Madrid.

Bosch, A. (1985): «La Cova del Pasteral. Un Jaciment Neolític a la Vall Mitjana del Ter «, Homenatge al Dr. Josep Maria Colominas, vol. II, Banyoles, pp.29-56.

Caballero, A. (1983): La pintura rupestre esquemática de la vertiente septentrional de Sierra Morena (provincia de Ciudad Real) y su contexto arqueológico. Museo de Ciudad Real.

CAmpbelL, A.C. (1983): Guía de campo de la flora y fauna de las costas de España y de Europa. Omega. Barcelona.

Carrobles, J. y Méndez-Cabeza, V. M. (1990): «Introducción al estudio del Calcolítico en La Jara toledana», Anales Toledanos, XXVIII, Toledo, pp. 7-24.

Cronyn, J. M. (1990): The elements of archaeological conservation. Ed. Routledge. New York.

Delibes, G. y Fernández Miranda, M. (1993): Los orígenes de la civilización. El Calcolítico en el Viejo Mundo. Síntesis. Madrid.

DuMEZIL, G. (1997): Mito y epopeya, vol. Il. Tipos épicos indoeuropeos: un héroe, un brujo, un rey. FCE. Méjico. 
Espadas, J. J. (1984): «Prospecciones en el Campo de Montiel II: El Cerro de los Conejos, Villanueva de los Infantes (Ciudad Real). Nuevo yacimiento del Calcolítico- Bronce», Cuadernos de Estudios Manchegos, 15, Instituto de Estudios Manchegos. Ciudad Real, pp. 11-39.

ESPADAS, J. J. et al. (1986): «El poblado calcolítico «El Castellón» (Villanueva de los Infantes, Ciudad Real). Informe de la II campaña de excavación», Oretum, II, Ciudad Real, pp. 233-248.

- (1987): «Memoria preliminar de las excavaciones del yacimiento calcolítico El Castellón (Villanueva de los Infantes, Ciudad Real), Oretum, III, Ciudad Real, pp. 39-78.

EStAVILLO, D. (1950): “Yacimientos arqueológicos de Campo de Criptana (La Mancha)», Actas y Memorias de la Sociedad Española de Antropología, Etnografía y Prehistoria, t. XXV, Madrid, pp. 37-50.

FÁbregas, R. y RuIz GÁlvez, M. ${ }^{a}$ L. (1997): «El Noroeste de la Península Ibérica en el III y II. ${ }^{\circ}$ Milenios: propuestas para una síntesis», Sagvntum, 30 (II), pp. 191-226.

Fernández MARTíneZ, V. M. (2006): Una Arqueología crítica. Ciencia, ética y política en la construcción del pasado. Crítica. Barcelona

FernÁNDEZ-Posse, M. ${ }^{a}$ D. et al. (1999): «Meseta Sur», en Delibes, G. y Montero, I.: Las primeras etapas metalúrgicas de la Península Ibérica, Fundación Ortega y Gasset. Madrid, pp. 217-236.

FERnÁNDEZ RodRígueZ, M. (2003): Las pinturas rupestres esquemáticas del Valle de Alcudia y Sierra Madrona. Mancomunidad de Municipios del Valle de Alcudia y Sierra Madrona.

Garrido-PenA, R. (2000): El Campaniforme en La Meseta Central de la Península Ibérica. BAR Internacional Series.

GoÑI, A. et al. (1999): «La tecnología de los elementos de adorno personal en materias minerales durante el Neolítico Medio. El ejemplo del poblado de Cabecicos Negros (Almería)», II Congrés del Neolitic a la Península Ibèrica. Sagvuntum-Plav, Extra-2, Universidad de Valencia, pp. 163-170.

Guiral, C. y ZarzaleJos, M. (2003): Arqueología (vol. l). UNED. Madrid.

GutiÉRREZ, C. et al. (2000): “ El enterramiento múltiple del Abrigo de Cueva Maturras (Argamasilla de Alba, Ciudad Real) », en Benítez de Lugo, L. (coord.): El Patrimonio arqueológico de Ciudad Real. Métodos de trabajo y actuaciones recientes, UNED (Valdepeñas, Ciudad Real), pp. 43-65.

HARO, J. de y VELA, F. (1988): «Los yacimientos del Calcolítico y del Bronce en el nordeste de la provincia de Ciudad Real», I Congreso de Historia de Castilla- La Mancha, (Ciudad Real, 1986), Tomo II, Junta de Comunidades de Castilla-La Mancha, pp. 272-282.

HuRTADO, V. (1984): «El Calcolítico en la cuenca media del Guadiana y la necrópolis de La Picotilla», Actas de la Mesa Redonda sobre Megalitismo Peninsular, Sociedad de Amigos de la Arqueología. Madrid, pp. 51-76.

Hurtado, V. (dir.) (1995): El Calcolítico a debate. Junta de Andalucía. Sevilla.

Kunst, M. (coord.) (1995): «Origens, estructuras e relaçoes das culturas calcolíticas da Península Ibérica», en Actas das I Jornadas Arqueológicas de Torres Vedras (1987). Lisboa.

LÓPEZ FERNÁNDEZ, F. J. y BLANCO, A. (1993): «Algunos yacimientos en altura en la Comarca de Almadén (Ciudad Real): Sierras de la Virgen del Castillo y Cordoneros», en Actas del XXII Congreso Nacional de Arqueología, vol. II, Vigo, pp. 89-94.

MacARRo, J. A. y Silva, J. F. (1990): «Un hábitat campaniforme en Baranatoba (Sigüenza, Guadalajara)», en Wad-Al-Hayara, n. ${ }^{\circ}$ 17, Guadalajara, pp. 43-66.

Maluquer De Motes, J. (1971): «Un hallazgo eneolítico en Almodóvar del Campo (Ciudad Real)», Pyrenae V-VII, Barcelona, pp. 158-161.

ManzanARes, A. et al (2000): Guía de Castilla La Mancha: espacios naturales. Junta de Comunidades de Castilla-La Mancha. Toledo (5. a edición).

Mapa Geológico (1. a serie)(1928-1972). Hoja 738 del Instituto Geológico y Minero de España.

Mapa Geológico (1970). Hoja n. ${ }^{\circ} 61-200$ del Instituto Geológico y Minero de España.

MARTín, D. et al. (2002): «La Cueva de El Toro (El Torcal de Antequera, Málaga)», II Simposio de Prehistoria, Fundación Cueva de Nerja (Málaga), pp. 68-89.

MARTínez GonZÁlez, J. M. (1988): «Cerámicas campaniformes de la Provincia de Cuenca», Trabajos de Prehistoria, n. ${ }^{\circ}$ 45, Madrid, pp. 123-142.

MARtínez SAStRe, V. y VALIENTE, J. (1990): «Un asentamiento campaniforme en las Tetas de Viana (Viana de Mondéjar, Guadalajara), Wad-Al-Hayara, 17, Guadalajara, pp. 7-42.

Muñoz AmiliBia, A. M.a (2001): «El Calcolítico en la Península lbérica», en VV.AA.: Prehistoria, t. II, pp. 329-365. UNED. Madrid.

PAscual, J. L. (1998): Utillaje óseo, adornos e ídolos neolíticos valencianos. S.I.P. - Diputación de Valencia. Valencia.

PÉREZ, J. (1985): «Estudio arqueológico del Campo de Montiel», Oretum, I, pp. 175-237.

Poyato, C. y EspadAs, J. J. (1989): «El Castellón, un importante yacimiento con campaniforme en Villanueva de los Infantes, Ciudad Real», I Congreso de Historia de Castilla-La Mancha, vol. 2, pp. 207-211. 
- (1994): «El Cerro de El Castellón (Villanueva de los Infantes, Ciudad Real): la cabecera del Jabalón durante el III Milenio", en VV.AA.: Arqueología en Ciudad Real, Junta de Comunidades de CastillaLa Mancha. Toledo, pp. 41-68.

POYATO, C. y GALÁN C. (1978-79): «Hallazgo de materiales campaniformes en Oretum (Granátula de Calatrava, Ciudad Real)», Cu.PA.UAM, 5-6. Madrid.

Querol, M. ${ }^{a}$ A. y MARTínez, B. (1996): La gestión del Patrimonio Arqueológico en España. Alianza Universidad Textos. Madrid.

RoJAS, J. M. (1987): «La Huerta del Diablo: un posible asentamiento calcolítico con muralla circular», Trabajos de Prehistoria, 44, Madrid, pp. 271-287.

- (1989): «Relación hábitat-economía en el mundo campaniforme toledano», Congreso de Historia de Castilla- La Mancha, tomo I, Junta de Comunidades de Castilla-La Mancha, pp. 199-206.

ROJAS, J. M. y VILLA GonzÁLEZ J. R. (1995): «Una inhumación individual de época neolítica en Villamayor de Calatrava (Ciudad Real), Rubricatum 1, Actes I Congrés del Neolitic à la Península Ibérica, vol. 2, pp. 509-519.

- (2000): «Primeros datos sobre el Neolítico en Ciudad Real. La tumba de Villamayor de Calatrava», en Benítez de Lugo, L. (coord.): El Patrimonio arqueológico de Ciudad Real. Métodos de trabajo y actuaciones recientes, UNED (Valdepeñas, Ciudad Real), pp. 7-21.

RoJAS, J. M. y Gómez, A. J. (2000): « Intervención arqueológica en el yacimiento de Huerta- Plaza (Poblete) y su relación con otros yacimientos arqueológicos de la provincia de Ciudad Real, en Benítez de Lugo, L.: El Patrimonio arqueológico de Ciudad Real. Métodos de trabajo y actuaciones recientes, UNED (Valdepeñas, Ciudad Real), pp. 21-43.

Ruiz TABOADA, A. (1998): La Edad del Bronce en la provincia de Toledo: La Mancha y su entorno. Diputación de Toledo. Toledo.

SEASE, C. (1987): A conservation manual for the field archaeologist. University of California, Los Angeles, USA.

SIRET, E. y SIRET, L. (1890): Las primeras Edades del Metal en el Sudeste de España. Resultados de las excavaciones hechas por los autores desde 1881 hasta 1887. Barcelona. Ed. Facsímile de la Dirección General de Cultura de la Región de Murcia (2006).

TEN, R. (1979): «Un nuevo tipo de cuenta-colgante en el Neolítico catalán», en XV Congreso Nacional de Arqueología, Zaragoza, p. 135.

Teruel, M. S. (1986): «Objetos de adorno en el Neolítico de Andalucía Occidental. Síntesis tipológica», Cuadernos de Prehistoria de la Universidad de Granada, n. ${ }^{\circ} 11$, Granada, pp. 9-26.

UtRILLA, P. y BALLDELLOU, V. (1995-1996): «Cueva del Moro de Olvena», Bolskan, 12-13. Huesca.

VALLESPI, E. et al. (1985): Materiales del Neolítico Final - Eneolítico de la Vega de Los Morales (Aldea del Rey, Ciudad Real). Museo de Ciudad Real. Ciudad Real.

ValLESPí, E. et al. (1985): «Materiales líticos tallados del Eneolítico y Bronce de La Mancha de Ciudad Real», Oretum, I, Ciudad Real, pp. 81-124. 